\title{
Making an Unstable World more Accessible: Using Universal Design to make Collections and Exhibits Memorable for People of all Abilities
}

\author{
Steven M. Sullivan ${ }^{\ddagger}$ \\ ‡ Hefner Museum of Natural History, Miami University, Oxford, Ohio, United States of America
}

Corresponding author: Steven M. Sullivan (sulliv55@miamioh.edu)

Received: 10 Apr 2018 | Published: 13 Jun 2018

Citation: Sullivan S (2018) Making an Unstable World more Accessible: Using Universal Design to make

Collections and Exhibits Memorable for People of all Abilities. Biodiversity Information Science and Standards 2: e25666. https://doi.org/10.3897/biss.2.25666

\begin{abstract}
Make your collections memorable and accessible to audiences of all abilities by incorporating the principles of universal design (UD) in your museum exhibits. Universal design provides equitable access to resources, much the way that curb cuts improve access to roads and sidewalks. Museums spend considerable effort protecting specimens from agents of deterioration but this usually means that only one sense - vision - is employed in our exhibits. Providing greater accessibility may seem daunting, expensive, or dangerous for specimens but, by considering a few principles during exhibit development, UD is readily implemented and can make displays more effective than ever for people of all abilities, levels of understanding, and backgrounds. This is because UD goes beyond simple accessibility, it generates innovative solutions through the creative application of seven basic principles: equitable use, flexibility in use, simple and intuitive use, perceptible information, tolerance for error, low physical effort, and effective size and space for approach and use.
\end{abstract}

We will discuss how the principles of UD are fundamental to good exhibit design and can be especially effective in a natural history setting - both in the gallery as well as the classroom - because we can use authentic objects that are largely identical to the display specimens. Such authentic and multisensory products encourage empathy and biophilia, 
increase specimen and visitor safety, and improve overall quality of service. We will also show how our institution has incorporated students into the process of design, evaluation, and construction of UD exhibits as a way to both include diverse perspectives in the design process and as a way to train science communicators of all kinds.

\section{Keywords}

accessibility, equitable use, exhibit design, universal design principles, exhibition, formal and informal education, authentic objects

\section{Presenting author}

Steven M. Sullivan

\section{Presented at}

SPNHC 2018 